\title{
Liver Cirrhosis: Assessment of Patients Nutritional Status at Assiut University Hospital.
}

\author{
Shaymaa S. Khalil, Mohamed K. El-Sayed Youssef, Mimi M. Mekkawy \& Mohamed O. Abdelmalek \\ Assistant Lecturer of Adult Nursing, Faculty of Nursing/ Assiut University, Egypt. \\ Professor of Food Science and Technology, Faculty of Agriculture, Assiut University, Egypt. \\ Assistant professor of Adult Nursing, Faculty of Nursing, Assiut University, Egypt. \\ Lecturer of Tropical Medicine \& Gastroenterology, Faculty of Medicine, Assiut University, Egypt.
}

\begin{abstract}
Death rate of patients with liver cirrhosis is $41.6 \%$ in Egypt. It is important to assess the nutritional status of this group of patients because these patients suffer from protein-calorie malnutrition. Aim: Assessment of nutritional status in patients with liver cirrhosis in Assiut university hospital.Patient and Methods: 60 adult patients with liver cirrhosis as a study group were conducted at Tropical Medicine and Gastroenterology Department at Assiut University hospital. Tools utilized for data collection were :( I) patient assessment and (II) nutritional assessment. Results: The main causes of patients with liver cirrhotic were HCV and HBV infection. Malnutrition was prevalent in $85 \%$ of patients. The most common malnutrition risk factors were dry mouth, taste alteration, food intolerance, multiple medications and the presence of ascites. Conclusions: the majority of patients with decompensated liver cirrhosis were malnourished regardless the etiology of liver cirrhosis. Identifying the patients that are approaching the state of malnutrition by simple and easily applied methods is necessary in order to provide nutritional support. Recommendations: Nutritional support and regimen, advice and guidelines by dietitian should be undertaken for all cirrhotic patients to prevent the occurrence of complications of malnutrition and improve clinical outcome.
\end{abstract}

\section{Keywords :Nutritional Assessment \& Liver Cirrhosis.}

\section{Introduction}

Liver cirrhosis is a chronic hepatic disease characterized by diffuse destruction and fibrotic regeneration of hepatic cells. As necrotic tissue yields to fibrosis, this disease alters the liver structure and normal vasculature, impairs blood and lymph flow, and ultimately causes hepatic insufficiency [WHO, 2004 and Black and Hawks, 2009]. The incidence of cirrhosis is increasing in the developed world, mainly because of the life style factors which lead to its development [Walsh \& Crumbie, 2007].

According to the World Health Organization, there is about 3\% of the world's population is infected with Hepatitis $\mathrm{C}$ virus $(\mathrm{HCV})$ and that there are more than 170 million chronic carriers who are at risk of developing liver cirrhosis and/or liver cancer. More than 240 million people have chronic (long-term) liver infections. More than 780000 people die every year due to the acute or chronic consequences of hepatitis B. [Muhlberger et al., 2009 \& WHO, 2014].

Available studies indicated that liver cirrhosis developed in $4 \%$ to $24 \%$ of persons after 20 years of infection with $\mathrm{HCV}$. These estimates of cirrhosis risk are influenced strongly by the population studied and cohort recruitment methods [Guiltinan, 2008]. Hepatitis $\mathrm{C}$ virus (HCV) is recognized as a major threat to global public health, especially in Egypt which has possibly the highest HCV prevalence in the world; $10 \%-20 \%$ of the general populations are infected. HCV is the leading cause of liver cirrhosis, hepatocellular carcinoma (HCC) and chronic liver disease in this country [Zaltron et al., 2012].

Frequent finding in patients with liver cirrhosis is protein-calorie malnutrition (PCM), leading to severe consequences to the general state and clinical evaluation of the patient. It had been demonstrated that PCM is an independent risk factor for death among patients with chronic hepatic disease, contributing to the emergence of more severe complications in cirrhotic patients, such as ascites, hepatic encephalopathy, and infections. Multiple factors which are common to the underlying disease directly contribute to malnutrition, among them; anorexia, nausea, deficient food intake and absorption and catabolic state [Bianchi et al., 2008]. In addition, the many dietary restrictions used to control symptoms and specific complications, such as ascites and hepatic encephalopathy, aggravate the nutritional status, predisposing the patients to infections and worsening of the functional hepatic status [OldeDamink et al., 2009].

In spite of the well-known impact on morbidity and mortality, malnutrition in cirrhotic patients is still under diagnosed and untreated in clinical practice. Most of the traditional parameters for nutritional assessment are not reliable markers of malnutrition in this population. Body weight, BMI, weight loss, and body cell mass estimated by bio impedance analysis, 
are affected by fluid retention. The concentration of plasma proteins (albumin and pre-albumin) reflects liver impairment more than nutritional deficits [Nardi et al., 2009].

Nutritional support for preventing and treating of malnutrition in liver cirrhosis should include: assessment of nutritional status, dietetic counselling for: adequate and balanced diet, frequent meals and late-evening snack, alcohol withdrawal, oral nutritional supplements (complete formulas), artificial nutrition (enteral nutrition as first choice), and vitamin and mineral supplementation as thiamine, folate, calcium, vitamin D3, vitamin A, vitamin $\mathrm{E}$, zinc and magnesium according to specific needs)[ Nardi et al., 2009].

The nurse has a major role in caring for patients with liver cirrhosis through assessment the patient for subjective complaints such as malaise, fatigue, pruritus (itching), nausea, anorexia, and abdominal pain. Objective data, such as baseline weight, vomiting, pale stools, amber- or dark colour (teacoloured) urine, and jaundice, are recorded. The patient's vital signs are taken, and a low-grade fever or any abnormal bruising or bleeding is reported immediately. Assessment the patient for knowledge of disease process and how to prevent spread of the disease is necessary [Linda and Paula, 2009].

Screening all patients with chronic liver disease for nutritional abnormalities can identify those at risk of developing preventable complications. The initiation of nutritional therapy has the potential to reduce the risk of such complications, and to improve the overall mortality rate. [Amin and Law, 2007].

\section{The Aims of the Study}

To assess the nutritional status of patients with liver cirrhosis at Assiut university hospital.

\section{Research question}

What is the nutritional status of the patients with liver cirrhosis at Assiut University hospital?

\section{Significance of the Study}

According to the World Health Organization (WHO), there is about $3 \%$ of the world's population is infected with Hepatitis $\mathrm{C}$ virus (HCV) and there were more than 170 million chronic carriers who are at risk of developing liver cirrhosis and/or liver cancer[Muhlberger, 2009]. Death rate of liver cirrhosis is $41.6 \%$ in Egypt [WHO, 2004], there was an increase in incidence and prevalence of liver cirrhosis. It was important to assess the nutritional status of this group of patients because these patients suffer from protein-calorie malnutrition which was contributing to severe complications such as ascites, hepatic encephalopathy and infections and it causes significant health- related quality of life (QOL) impairment and morbidity.1840 patients(3.4\%) with liver cirrhosis were reported in Tropical Medicine and Gastroenterology department at Assiut University Hospital through 2014.

\section{Patients And Methods}

Research design:

Descriptive research design was utilized in this study. subject

\section{Technical design}

Setting:

The study was conducted in the Tropical Medicine and Gastroenterology department at Assiut University Hospital from January 2014 to May 2014

\section{Subjects}

Sample

Random sixty adult patients diagnosed with liver cirrhosis with Child class A and B only, patient's age from 18 years to 65 years, and ability to complete the participation in the research regardless educational level.

\section{Exclusive Criteria}

- Patient with Child class(C) liver cirrhosis, hepatic coma, renal failure, diabetes mellitus, and cancer.

\section{Tools}

Tool I: patient assessment sheet

It was developed by the researcher after reviewing of literature; it consisted of two parts:

Part (1): Personal and Medical Data

Part (2): Child-Pugh score:

Tool II: Nutritional assessment sheet:

This sheet is to cover data related to patient nutritional status and includes four parts:

Part (1): Risk factors affecting nutritional status, Part (2): Anthropometric measurements:

A) Patient weight in $\mathrm{kg}$.

B) Patient height in $\mathrm{cm}$.

C) $\mathrm{BMI}=\left(\right.$ Weight in $\mathrm{kg} /$ height in $\left.\mathrm{m}^{2}\right)$.

D) Triceps skin fold thickness (TSF):

Measure mid-arm circumference (MAC):

F) Calculate mid-arm muscle circumference (MAMC):

G) Calf circumference using measuring tape:

Part (3): Biochemical measurements:

Part (4): Mini- Nutritional Assessment (MNA) (malnutrition indictors score)

Methods

Operational Design

This study was conducted through:

- Tools development.

Tool I: patient assessment sheet

It was developed by the researcher after reviewing of literature; it consisted of two parts: 


\section{Part (1): Personal and Medical Data}

Socio-demographic variables of study sample $(60$ patients) patient's age, sex, level of education, occupation, marital status, residence, etiology, ascites, oesophageal varices, jaundice, essential medication data, ......etc.). This includes 27 questions.

The interview questionnaire sheet was administered by the researchers to the patients for answering all its components.

\section{Part (2): Child-Pugh score:}

Modified Child-Pugh scale (Child et al., 1964 was developed by Pugh in1973 [Pugh et al., 1973]. To rank severity of liver disease based on signs and the findings.

Table (1): Child-Pugh score

\begin{tabular}{|l|c|c|c|}
\hline $\begin{array}{l}\text { Clinical } \\
\text { variable }\end{array}$ & 1 point & 2 point & 3 point \\
\hline Bilirubin & $\begin{array}{c}<\mathrm{mg} / \mathrm{dl} \\
(34 \mathrm{UM} / \mathrm{l})\end{array}$ & $\begin{array}{c}2-3 \mathrm{mg} / \mathrm{dl} \\
(34-50 \\
\mathrm{UM} / \mathrm{l})\end{array}$ & $\begin{array}{c}>3 \mathrm{mg} / \mathrm{dl} \\
(50 \mathrm{UM} / \mathrm{l})\end{array}$ \\
\hline Albumin & $>3.5 \mathrm{~g} / \mathrm{dl}$ & $3.5-2.8$ & $<2.8$ \\
\hline $\begin{array}{l}\text { PT } \\
\text { prolongation } \\
\text { (INR) }\end{array}$ & $\begin{array}{c}<4 \mathrm{~seconds} \\
(<1.7)\end{array}$ & $\begin{array}{c}(4-6) \\
\text { seconds } \\
(1.7-2.3)\end{array}$ & $\begin{array}{c}>6 \text { seconds } \\
(>2.3)\end{array}$ \\
\hline Ascites & Absent & $\begin{array}{c}\text { Mild- } \\
\text { Moderate }\end{array}$ & $\begin{array}{c}\text { Severe/Refr } \\
\text { actory }\end{array}$ \\
\hline $\begin{array}{l}\text { Encephalo } \\
\text { pathy }\end{array}$ & Absent & Mild (I-II) & $\begin{array}{c}\text { Severe (III- } \\
\text { IV) }\end{array}$ \\
\hline
\end{tabular}

Child-Pugh Bottom interpretation Score:

Class $A=5-6$ points $\quad$ Class $B=7-9$ points

Class $C=10-15$ points

Tool II: Nutritional assessment sheet

This sheet is to cover data related to patient nutritional status and includes four parts

Part (1): Risk factors affecting nutritional status, this part aimed to identify the risk factors which effect on nutritional status and contained 17 questions such as (dry mouth, taste alteration, vomiting, diarrhoea, constipation, failure to thrive: combination of three or five symptoms, including: weakness, slow walking speed, low physical activity and unintentional weight loss, Exhaustion. ...etc.).

Part (2): Anthropometric measurements

D) Patient weight in $\mathrm{kg}$.

E) Patient height in $\mathrm{cm}$.

F) $\mathrm{BMI}=\left(\right.$ Weight in $\mathrm{kg} /$ height in $\left.\mathrm{m}^{2}\right)$.

Standards classify a BMI for an adult at less than 18.5 as underweight, a BMI between 25 and 29 as overweight and a BMI greater than 30 as obese. A healthy BMI for adults is considered between 18.5 and 24.9.

G) Triceps skin fold thickness (TSF): [Nettina, 2010]. By using a digital caliper.

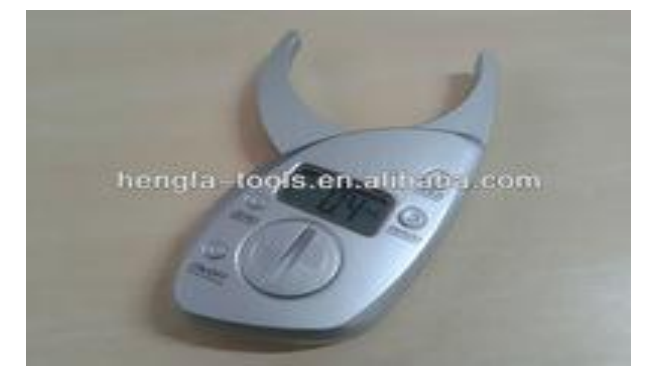

Fig (1), shows the balance device that used in measuring triceps skin fold thickness of the patients.

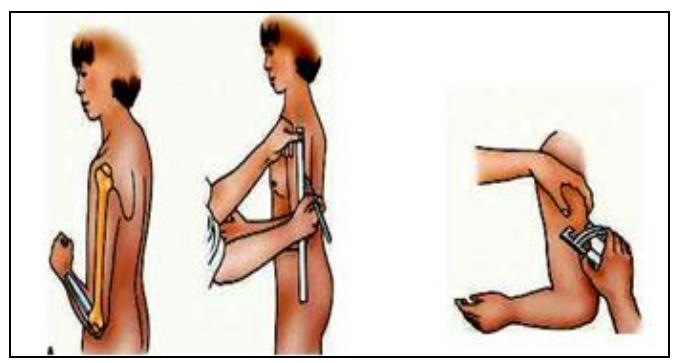

Fig (2), shows the steps of measuring triceps skin fold thickness of the patients.

H) Measure mid-arm circumference (MAC) normal values are $18.5-25.5 \mathrm{~cm}$ for adults [Weber $\boldsymbol{\&}$ Kelley, 2007]. Using measuring tape.
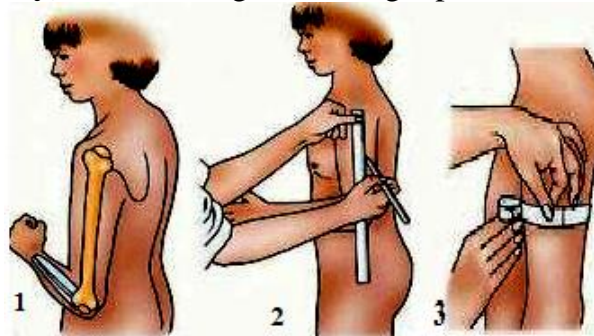

Fig (3), shows the steps of measuring mid-arm circumference of the patients.

Calculate mid-arm muscle circumference $($ MAMC $)=$ MAC- (0.314(TST)) [Weber and Kelley, 2007].

D) Calf circumference using measuring tape.

This part aimed to assess patient anthropometric measurements.

Part (3): Biochemical measurements

Biochemical assessments reflect both the tissue level of a given nutrient and any abnormality of metabolism in the utilization of nutrients. These determinations are made from studies of serum complete blood count; (haemoglobin, white blood cells, mean corpuscular volume (MCV), mean corpuscular haemoglobin (MCH), mean corpuscular haemoglobin concentration (MCHC), platelet count, and total lymphocyte count), serum albumin, prothrombine time \& concentration, and bilirubin.

Part (4): Mini- Nutritional Assessment (MNA) (malnutrition indicators score) [Stephen, 2012].

The aim of this part is a rapid and reliable tool for evaluating the nutritional status. It is composed of 18 
items.(Dry mouth, taste alteration, vomiting, diarrhea, constipation, poor fitting, food allergies, transportation problems, inability to prepare meals, loneliness, failure to thrive, history of OTC drugs, acute or chronic pain, recent surgery, multiple medications, low income, substance abuse, and snake).

Malnutrition indicator Score.

- Malnourished $(\mathrm{MNA}<17)$,

- At risk of malnutrition $(17<\mathrm{MNA}<24)$, and

- Well nourished (MNA > 24).

- Content validity was done by expertise (one nutritional staff), (one medical staff) \& (one nursing staff) from the medical-surgical nursing field. Modifications were made accordingly, and then the tools were designed in their final format and tested for reliability using internal consistency for all of the tools which were measured using Cronbach test. The tools proved to be reliable (0.73.0.71 and 0.81 , respectively).

- An official permission was obtained from the head of the Tropical Medicine and Gastroenterology department at Assiut University Hospital to conduct the study.

Ethical considerations

- An informed consent was obtained from patients to participate in the study and the nature and purpose of the study were explained to them.

- The researchers initially introduced themselves to all optional subjects and they were assured that the collected data would be absolutely confidential.

- They were informed that participation is voluntary and that they could withdraw at any time of the study.

- Confidentiality of the patient's data was ascertained. Confidentiality and anonymity were assured.

- Patient's names were coded for data entry so that their names could not be identified. Then, through this patient's interview.

\section{Pilot study}

- A pilot study was conducted on $10 \%$ of the sample (6 patients) in a selected setting to evaluate the applicability \& clarity of the tools. According to this pilot study, the required modifications were made. Those patients who were involved in the pilot study were included in the study.

- Data was obtained from the study patients to fill in Tools: I and II. At initial interview, the researcher introduced herself to initiate the line of communication, explain the nature $\&$ purpose of the research and fill out the patient assessment sheet (tool I) which contains; Personal and Medical Data Sheet and Child-Pugh score.

- Tool II: Nutritional assessment sheet contains; risk factors affecting nutritional status, anthropometric measurements, Biochemical measurements and Mini- Nutritional Assessment (MNA) (malnutrition indictors scores).

\section{Statistical design}

Data entry was done using a compatible personal computer by the researcher. All data was entered into statistical packages for the social sciences (SPSS) version 17.0 (Chicago, Illinois, USA) software for analysis and Excel for figures. The content of each tool was analyzed, categorized and then coded by the researcher. Data were presented using descriptive statistics in the form of frequencies and percentages for qualitative variables, and means and standard deviations for quantitative variables. Pearson's correlation analysis was used for assessment of the inter-relationships among quantitative variables. Using chi-square to determine significance for nonparetic's variables. Statistical significance difference was considered when statistical significance was considered at $\mathrm{p}$-value $<0.05$.

Data related to socio-demographic characteristics of cirrhotic liver patients of the studied sample were initially collected as a baseline data, and then the nutritional assessment form was completed, each patient was interviewed individually. Data were analyzed using descriptive statistics in the form of frequencies and percentages for qualitative variables, and means and standard deviations for quantitative variables. Correlation Coefficient (r) analysis was used for assessment of the inter-relationships among quantitative variables. Using chi-square to determine significance from non significance variables. Statistical significance difference was considered when statistical significance was considered at $\mathrm{p}$ value $<0.05$

\section{Limitations of the study}

- Missed patients during the period of the study for that the research takes a long period of data collection.

- The researchers start the study with 115 patients. 20 patients died and 15 were missed during followup stage so they excluded from the study.

- Limitation of this study is that the investigation findings are limited in generalizability because the sample was selected from one geographical area in Arab Republic of Egypt (Tropical Medicine and Gastroenterology department at Assiut University Hospital). 


\section{Results}

Table (1): Socio-demographic characteristics of studied patients $(n=60)$.

\begin{tabular}{|c|c|c|}
\hline \multicolumn{3}{|c|}{ Study group $(\mathrm{n}=60)$} \\
\hline & N. & $\%$ \\
\hline Age groups Mean \pm SD & \multicolumn{2}{|c|}{$56.0 \pm 8.1$} \\
\hline $18>30$ years & 1 & 1.7 \\
\hline $30>40$ years & 2 & 3.3 \\
\hline $40>50$ years & 9 & 15.0 \\
\hline $50>65$ years & 48 & 80.0 \\
\hline Gender & & \\
\hline Male & 26 & 43.3 \\
\hline Female & 34 & 56.7 \\
\hline Marital Status & & \\
\hline Single & 3 & 5.0 \\
\hline Married & 50 & 83.3 \\
\hline Widow & 7 & 11.7 \\
\hline Level of education & & \\
\hline Illiterate & 41 & 68.3 \\
\hline Read and write & 0 & 0.0 \\
\hline Basic education & 3 & 5.0 \\
\hline Secondary/ deplume & 12 & 20.0 \\
\hline University & 4 & 6.7 \\
\hline Occupational status & & \\
\hline House wife & 33 & 55.0 \\
\hline Worker & 8 & 13.3 \\
\hline Farmer & 2 & 3.3 \\
\hline Unemployed & 0 & 0.0 \\
\hline Retired & 8 & 13.3 \\
\hline Employer & 9 & 15.0 \\
\hline Residence & & \\
\hline Urban & 9 & 15.0 \\
\hline Rural & 51 & 85.0 \\
\hline Etiology of liver cirrhosis & & \\
\hline $\mathrm{HCV}$ & 42 & 70.0 \\
\hline Unknown causes & 1 & 1.7 \\
\hline $\mathrm{HBV}$ & 6 & 10.0 \\
\hline HCV \& Bilharzia & 6 & 10.0 \\
\hline HCV \& others & 5 & 8.3 \\
\hline
\end{tabular}

Table (2): Clinical presentations of studied patients $(n=60)$.

\begin{tabular}{|l|c|c|}
\hline \multicolumn{3}{|c|}{ Study group (n=60) } \\
\hline \multicolumn{3}{|c|}{ N. } \\
\hline Bleeding tendency & \multicolumn{1}{|c|}{} \\
\hline Yes & 33 & 55.0 \\
\hline No & 27 & 45.0 \\
\hline Ascites & 34 & 56.7 \\
\hline Yes & 26 & 43.3 \\
\hline No & \multicolumn{3}{|c|}{} \\
\hline Splenomegaly & 24 & 40.0 \\
\hline Yes & 36 & 60.0 \\
\hline No & & \\
\hline
\end{tabular}




\begin{tabular}{|l|c|c|}
\hline \multicolumn{3}{|c|}{ Study group (n=60) } \\
\hline \multicolumn{3}{|c|}{ N. } \\
\hline Jaundice & \multicolumn{2}{|c|}{} \\
\hline Yes & 25 & 41.7 \\
\hline No & 35 & 58.3 \\
\hline Severity of liver cirrhosis & 10 & 16.7 \\
\hline Class A & 50 & 83.3 \\
\hline Class B & \multicolumn{3}{|c|}{} \\
\hline
\end{tabular}

Table (3): Risk factors for malnutrition in studied patients $(n=60)$.

\begin{tabular}{|l|c|c|c|c|}
\hline \multirow{2}{*}{\multicolumn{1}{|c|}{ Risk factors }} & \multicolumn{3}{c|}{ Study group (n=60) } \\
\cline { 2 - 5 } & \multicolumn{3}{c|}{ Yes } & \multicolumn{2}{c|}{ No } \\
\cline { 2 - 5 } & $\mathbf{N}$ & $\mathbf{\%}$ & $\mathbf{N}$. & \% \\
\hline Dry mouth & 51 & 85.0 & 9 & 15 \\
\hline Taste alteration & 40 & 66.7 & 20 & 33.3 \\
\hline Vomiting & 17 & 28.3 & 43 & 71.7 \\
\hline Diarrhea & 6 & 10.0 & 54 & 90.0 \\
\hline Constipation & 25 & 41.7 & 35 & 58.3 \\
\hline Poor fitting or no dentures / poor dental health & 20 & 33.3 & 40 & 66.7 \\
\hline Food allergies or intolerance & 30 & 50.0 & 30 & 50.0 \\
\hline Transportation problems & 17 & 28.3 & 43 & 71.7 \\
\hline Inability to prepare meals & 25 & 41.7 & 35 & 58.3 \\
\hline Loneliness and /or depression & 25 & 41.7 & 35 & 58.3 \\
\hline Failure to thrive & 35 & 58.3 & 25 & 41.7 \\
\hline History of OTC drugs & 13 & 21.7 & 47 & 78.3 \\
\hline Acute or chronic pain & 26 & 43.3 & 34 & 56.7 \\
\hline History of surgery/trauma & 22 & 36.7 & 38 & 63.3 \\
\hline Multiple medications & 31 & 51.7 & 29 & 48.3 \\
\hline Low income & 20 & 33.3 & 40 & 66.7 \\
\hline
\end{tabular}

Table (4): Mean and SD for anthropometric measurements of studied patients $(n=60)$.

\begin{tabular}{|l|l|c|}
\hline \multicolumn{2}{|c|}{ Anthropometric measurements } & Study group(n=60) \\
\hline \multirow{2}{*}{ BMI } & M & $26.5 \pm 3.9$ \\
\cline { 2 - 3 } & F & $27 \pm 4.8$ \\
\hline \multirow{2}{*}{ Triceps skin fold thickness } & M & $1.1 \pm 0.6$ \\
\cline { 2 - 3 } & F & $1.3 \pm 0.6$ \\
\hline \multirow{2}{*}{ Mid-arm circumference } & M & $27.8 \pm 3.5$ \\
\cline { 2 - 3 } & F & $26.8 \pm 3.7$ \\
\hline Calf circumference & M & $33.9 \pm 3.2$ \\
\cline { 2 - 3 } & F & $33.3 \pm 4$ \\
\hline
\end{tabular}

M: male $\boldsymbol{F}$ : female 
Table (5): Biochemical measurements among the study group (n=60).

\begin{tabular}{|c|c|c|}
\hline & \multicolumn{2}{|c|}{ Study group $(n=60)$} \\
\hline & $\mathbf{N}$. & $\%$ \\
\hline \multicolumn{3}{|c|}{ Serum albumin } \\
\hline Low & 38 & 63.3 \\
\hline Normal & 22 & 36.7 \\
\hline Mean \pm SD & & \\
\hline \multicolumn{3}{|c|}{ Hemoglobin } \\
\hline Low & 34 & 56.7 \\
\hline Normal & 26 & 43.3 \\
\hline Mean \pm SD & & \\
\hline \multicolumn{3}{|c|}{ Hematocrit } \\
\hline Low & 39 & 65.0 \\
\hline Normal & 21 & 35.0 \\
\hline Mean \pm SD & & \\
\hline \multicolumn{3}{|c|}{ INR } \\
\hline Normal & 20 & 33.3 \\
\hline High & 40 & 66.7 \\
\hline Mean \pm SD & & \\
\hline \multicolumn{3}{|c|}{ Platelet count } \\
\hline Low & 48 & 80.0 \\
\hline Normal & 12 & 20.0 \\
\hline Mean \pm SD & & \\
\hline \multicolumn{3}{|c|}{ Serum Bilirubin } \\
\hline Normal & 27 & 45.0 \\
\hline High & 33 & 55.0 \\
\hline Mean+SD & \multicolumn{2}{|c|}{$26.6 \pm 68.6$} \\
\hline
\end{tabular}

Table (6): Percentage distribution of malnutrition indicator score of studied patients $(n=(60)$.

\begin{tabular}{|l|c|c|}
\hline \multicolumn{1}{|c|}{ Malnutrition Indicator } & \multicolumn{2}{c|}{ Cases (n=60) } \\
\cline { 2 - 3 } & $\mathbf{N .}$ & \% \\
\hline Malnourished & 40 & 66.7 \\
\hline At risk of malnutrition & 10 & 16.7 \\
\hline Normal nutritional status & 10 & 16.7 \\
\hline
\end{tabular}

$*$ =Significant difference $* *=$ highly significance $\quad N s=$ Non significant difference

Table (7): Malnutrition indicator score of studied patients ( $n=60)$ according to Child-Pugh Classes (A and B).

\begin{tabular}{|c|c|c|c|c|c|}
\hline \multirow[t]{2}{*}{ Malnutrition Indicator } & \multicolumn{4}{|c|}{$\begin{array}{c}\begin{array}{c}\text { Severity of liver disease (Child-Pugh Classes) } \\
\text { Class A }\end{array} \\
\text { Class B } \\
\end{array}$} & \multirow{2}{*}{$\begin{array}{r}\text { P. value } \\
0.131\end{array}$} \\
\hline & N. & $\%$ & N. & $\%$ & \\
\hline \multirow{3}{*}{$\begin{array}{l}\text { Malnourished } \\
\text { At risk of malnutrition } \\
\text { Normal nutritional status }\end{array}$} & 5 & 50.0 & 35 & 70.0 & \\
\hline & 3 & 30.0 & 7 & 14.0 & \\
\hline & 2 & 20.0 & 8 & 16.0 & \\
\hline
\end{tabular}


Table (8): Correlation between risk factors and malnutrition indicators scores of studied patients $(n=60)$.

\begin{tabular}{|c|c|c|c|c|c|c|c|}
\hline & \multicolumn{6}{|c|}{ Malnutrition Indicator } & \multirow{3}{*}{ P. value } \\
\hline & \multicolumn{2}{|c|}{$\begin{array}{l}\text { Malnourished } \\
\qquad \mathbf{N}=40\end{array}$} & \multicolumn{2}{|c|}{$\begin{array}{c}\text { At risk of } \\
\text { malnutrition } \\
\mathrm{N}=\mathbf{1 0}\end{array}$} & \multicolumn{2}{|c|}{$\begin{array}{c}\text { Does not suffer } \\
\text { from malnutrition } \\
\mathrm{N}=\mathbf{1 0}\end{array}$} & \\
\hline & $\mathbf{N}$. & $\%$ & $\mathbf{N}$. & $\%$ & $\mathbf{N}$. & $\%$ & \\
\hline Dry mouth & 38 & 95.0 & 8 & 80.0 & $\overline{5}$ & 50.0 & $0.021 *$ \\
\hline Taste alteration & 33 & 82.5 & 5 & 50.0 & 2 & 20.0 & $0.001 *$ \\
\hline Vomiting & 12 & 30.0 & 3 & 30.0 & 3 & 20.0 & 0.832 \\
\hline Diarrhea & 3 & 7.5 & 2 & 20.0 & 1 & 10.0 & 0.114 \\
\hline Constipation & 18 & 30.0 & 4 & 40.0 & 3 & 30.0 & 0.156 \\
\hline Poor fitting of dentures & 15 & 37.5 & 2 & 20.0 & 3 & 30.0 & 0.089 \\
\hline Food intolerance & 25 & 62.5 & 3 & 30.0 & 2 & 20.0 & $0.041^{*}$ \\
\hline Transportation problems & 11 & 27.5 & 3 & 30.0 & 3 & 30.0 & 0.480 \\
\hline Inability to prepare meals & 20 & 50.0 & 3 & 30.0 & 2 & 20.0 & 0.067 \\
\hline Loneliness / depression & 19 & 47.5 & 2 & 20.0 & 2 & 20.0 & 0.086 \\
\hline Failure to thrive & 25 & 62.5 & 5 & 50.0 & 5 & 50.0 & 0.166 \\
\hline History of OTC drugs & 10 & 25.0 & 2 & 20.0 & 1 & 10.0 & 0.183 \\
\hline Acute or chronic pain & 20 & 50.0 & 3 & 30.0 & 3 & 30.0 & 0.298 \\
\hline Recent surgery/trauma & 18 & 45.0 & 3 & 30.0 & 2 & 20.0 & 0.385 \\
\hline Multiple medications & 26 & 65.0 & 3 & 30.0 & 2 & 20.0 & $0.033 *$ \\
\hline Low income & 15 & 37.5 & 4 & 40.0 & 1 & 10.0 & 0.095 \\
\hline Child Class A & 5 & 12.5 & 3 & 30.0 & 2 & 20.0 & 0131 \\
\hline Child Class B & 35 & 87.5 & 7 & 70.0 & 8 & 80.0 & 0.131 \\
\hline Ascites & 30 & 75.0 & 3 & 30.0 & 1 & 10.0 & $0.004 *$ \\
\hline Jaundice & 20 & 50.0 & 3 & 30.0 & 2 & 20.0 & 0.201 \\
\hline Splenomegally & 19 & 47.5 & 3 & 30.0 & 2 & 20.0 & 0.092 \\
\hline
\end{tabular}

$*$ =Significant difference $* *=$ highly significance $\quad$ Ns $=$ Non significant difference

Table (1): Shows that; the majority of the study group $(n=60)$ were female, married, illiterate, housewife, from rural areas, $\mathrm{HCV}$ was the main cause of cirrhosis, and their age ranged from 51 to 65 years old.

Table (2): Shows that there was the majority of the study group had bleeding tendency and ascites, and most of them were Child class B.

Table (3:)This table shows that the most common malnutrition risk factors were dry mouth $(85 \%)$ and taste alteration(66.7\%), regarding all risk factors of malnutrition among cirrhotic patients.

Table (4): Clarifies that the mean value of anthropometric measurements of female patients was higher than male patients in BMI, TSFT, while it is lower than male patients in MAC and CC.

Table (5): Shows that the majority of patients had low value in serum albumin, hemoglobin, hematocrit and platelet count, and had higher values in serum Bilirubin and INR.

Table (6): This table shows the nutritional status of the study group was the majority of them suffered from malnutrition.
Table (7): Shows malnutrition is more common in patients with Child class B than in Class A but without statistically significant difference $(\mathrm{p}$-value $=$ $0.131)$

Table (8) This table clarifies that dry mouth, taste alteration, food intolerance, multiple medications and the presence of ascites are the main risk factors for malnutrition in our study.

\section{Discussion}

Based on the results of the present study; the majority of the patients were females were in the fifties, as regards the marital status, the majority were married. As regard the level of education, the majority were illiterate. These findings are consistent with Sallam(2007) who reported that; more than half of the study patients were illiterate. According to the study which was carried out by Vanderplas, Iiansen, De Boer, Stijnen,Passo, De man, \& Schalm., (2012), on a number of cirrhotic liver patients, it revealed that the majority of the sample had secondary education, this result disagreed with the 
present study which may be due to the different nature of the study population.

Cahill, Tryniszewski, Hubbard, Shaw, Andrews, Cynthia, Durkin \& Christina (1996), Buczko (2010), Vanderplas, Iiansen, De Boer, Stijnen,Passo, De man , \& Schalm., (2012), \& Jennifer, Suti \& Saab (2008), weren't in the same line with the current study finding which, mentioned that; liver cirrhosis is as twice as common in men than in women and agreed in prevalent among malnourished patients over age 50 years of age. In our study, females were more cooperative than male in participation.

In relation to patient's residence, The results of the present study agreed with study by Rao et al., (2013) who reported that; in Egypt, liver cirrhosis was more common in rural than urban regions because rural regions presented a suitable environment for developing a schistosomal infection due to exposure to canal water that may be polluted by snails that harbor the schistosomal parasite. Likewise, Abd elGhaffar (2004), added that in Egypt, liver cirrhosis with or without chronic active hepatitis constituted about $50 \%$ of all chronic liver diseases that met within Egypt and even higher percentage in rural Egypt. This means that cirrhosis is the commonest chronic liver disease in the country.

In relation to marital status and occupation, the present study revealed that the majority of male patients were married and work as employees and farmers. While most of the female patients were married and housewives., this result was supported by Rao, Naficy, Darwish, Darwish, Schisterman, Clemens, \& Edelman, (2013) \& Vanderplas, Iiansen, De Boer, Stijnen, Passo, De man , \& Schalm., (2012), finding according to the study which was carried out on a number of cirrhotic liver patients in Egypt which reported that the majority of the sample were working as farmers which put them at high risk for developing schistosomal infection and the majority of the patient were married.

The current study represented that; the majority of the study patients were infected with HCV and suffered from mild to moderate ascites and this result agrees with Sharif, Mohebbi, Tabtabaee, Saberi \& Gholamzadeh (2005), finding who stated that twenty-five to thirty-five percent of patients with chronic hepatitis $\mathrm{C}$ virus progress to cirrhosis. Hepatitis $\mathrm{C}$ virus (HCV) is recognized as a major threat to global public health, especially in Egypt which has possibly the highest $\mathrm{HCV}$ prevalence in the world; $10 \%-20 \%$ of the general populations are infected. HCV is the leading cause of liver cirrhosis, hepatocellular carcinoma (HCC) and chronic liver disease in this country.
Hassan, Zaghloul, EL- Serag, Soliman, Patt, ChaPp.ell, Beasley \& Hwang, (2001), and Faust \& Reedy (2006), added that, over the past decade, chronic hepatitis $\mathrm{C}(\mathrm{HCV})$ had replaced alcohol as the leading cause of cirrhosis. Cesario, Choure, \& Carey,(2011), reported that ascites was the most common major complication of cirrhosis and is an important landmark in the natural history of chronic liver disease. If observed for 10 years, approximately $60 \%$ of patients with cirrhosis developed ascites requiring therapy.

The results of the present study revealed that the severity of liver cirrhosis was classified according to Child-Pugh class most of them were in class B (83.3\%). This finding agrees with Tai, Siti, Mohd, Sanjay \& Sanjiv (2010), who reported that; all patients had advanced liver disease with 16 (44.4\%) cases of Child-Pugh B and 20 (55.6\%) cases of Child-Pugh C cirrhosis disagrees with Faiyaz, Memon, Afsar, Qadeer, \& Kumar (2007), who reported that; 109 patients were selected with 72 males and 37 females patient, classified according to Child class A, B \& C was (30, 38 \& 41; respectively) this is because the present study excluded patients Child class $\mathrm{C}$.

The present study revealed that; the most common risk factors for malnutrition are dry mouth, taste alteration, food allergies or intolerance, multiple medications and the presence of ascites. This result partially agrees with finding of ; Yao et al. (2009), Plauth \& Schutz (2002), Hogan \& Madayag (2004), Figueiredo, Perz, and Kondo, (2005), Carvalho \& Rober (2006), \& Kondrup (2007), who reported that; Multiple factors which are common to the underlying disease directly contribute to malnutrition, among them, anorexia, nausea, deficient food intake, maldigestion, malabsorption and catabolic state. In addition, the many dietary restrictions used to control symptoms and specific complications, such as ascites and hepatic encephalopathy, aggravate the nutritional status, predisposing the patients to infections and worsening of the functional hepatic status and David(2011), who added that, the liver plays a role in normal appetite regulation and liver disease may impair food intake

Likewise, the results agree with Anne \& Alan (2006), who reported that; many patients with the advanced liver disease had an altered sense of taste, which might be related to vitamin $\mathrm{A}$ and/or zinc deficiency, often experience early satiety that is related to mechanical compression from massive ascites.

Nardi, Ognana, Schiavo \& Caregaro, (2009) stated that skinfold anthropometry is considered a useful technique for assessment of body composition in 
patients with the chronic liver disease. It is value in detecting mild or moderate signs of malnutrition, which are difficult to recognize clinically. Likewise of Caregaro, Alberino, Amodio, Merkel, Bolognesi, \& Angeli, (1996) stated that because of limitations of other nutritional indexes, skinfold anthropometry repres

ents at present the most reliable clinical measure of nutritional status in patients with the chronic liver disease. Its correlation with survival could be used to improve the accuracy of the commonly used prognostic formulas.

Demling \& Desanti, (2004) reported that (MAC), (TSFT), (MAMC) are useful in identifying the most severely malnourished patients especially those with fluid retention as a result of the disease. On the other hand Lacy, Gabbard \& Crowell, (2008) reported that mild to moderate protein calorie malnutrition was found in liver cirrhosis, adults generally lose their body weight although edema may mask weight loss, triceps skin fold thickness and mid-arm muscle area are reduced below than normal range.

With reference to mean of anthropometric measurements, the study shows that male patients were higher than female patients in mid-arm circumference (MAC) and calf circumference (CC) while they are lower than female patients in TSFT. this result disagrees with Carvalho \& Rober (2006), who reported that fat reserves, evaluated by TSFT, were more depleted in females than in males $(48.6 \%$ and $26.6 \%$ ) regardless of the etiology of the cirrhosis. According to the study which was carried out by Fusha (2010) on patients with liver cirrhosis, which revealed that the mean values for (MAC) decreased in female more than male patients with liver cirrhosis.

In the present study application of malnutrition indicator scale on the studied patients revealed that most of malnourished are Child-Pugh Class (B). This was supported by Kawabe, Hashimoto, \& Yoshioka, (2008), who reported that the higher grade of the Child-Pugh classification was significantly more prevalent in the patients with moderate malnutrition than in those with mild malnutrition $(\mathrm{P}=$ $0.0001 * *)$.

The study reported that there was no significance difference between male and female patients and the majority of both having malnutrition and; while the minority of them had a risk for malnutrition. According to study which was carried out on a number of hospitalized cirrhotic patients by Campillo, Richardet, Scherman, \& Bories (2013), cirrhotic patients had a high prevalence rate of malnutrition, and most of them don't satisfy their nutritional requirements, so their caloric intake was decreased which is an independent risk factor for short-term mortality and according to study which was carried out by Gunsar, Raimondo, Jones, Terreni, Wong \& Patch (2006), (42\%) of the patients were well nourished, $(40 \%)$ were mildly or moderately malnourished and (18\%) were severely malnourished.

Pablo \& Alday, (2010) pointed out that the majority of them were malnourished on admission. Malnutrition is a complication of liver cirrhosis that should be treated together with the others complications Kondrup (2007) and Caregaro, Alberino, Amodio, Merkel, Bolognesi, \& Angeli, (1996) reported that nutritional disorders are common in both alcoholic and viral cirrhosis and are related to the severity of liver disease rather than to its etiology. This predisposing the patients to infections and worsening of the functional hepatic status Carvalho, \& Rober, (2006).

This specific conclusion that has been reached in the present study had been very well emphasized by Zeen El-Abedin (2011), who confirmed that counseling should be provided for all cirrhotic patients regarding nutritional support to prevent the occurrence of complications such as hepatic encephalopathy, hepato-renal syndrome and improve clinical outcome.

In conclusion, the present study findings support that nutritional assessment is an essential part of medical and nursing care for liver cirrhotic patients to identify who are nutritionally at risk.

\section{Conclusions}

Based on the results of the present study, it can be concluded that:

Based on nutritional assessment data such as anthropometric measurements, mini nutritional assessment combined with the additional of biochemical markers, the researchers found that, the majority of patients with decompensated liver cirrhosis were malnourished regardless the etiology of liver cirrhosis. The most common malnutrition risk factors were dry mouth, taste alteration, food intolerance, multiple medications and the presence of ascites.

\section{Recommendations}

Nutritional support, advice, and guidelines by dietitian of the nutritional regimen should be undertaken for all cirrhotic patients to prevent the occurrence of complications of malnutrition and improve clinical outcome.

Application of this study on the large different sample and geographical area. 


\section{References}

1. Abdel Ghaffar, Y., (2004): Hematology in Egypt 20 years ago, cirrhosis in Egypt, The Afro- Arab liver journal, 3 (1), Pp 33-58.

2. Amin, J., \& Law, M., (2007): Causes of death in hepatitis $\mathrm{B}$ and $\mathrm{C}$ : a methodological issue. Lancet, 370(9592), Pp 1033.

3. Anne, S., \& Alan, L., (2006): Nutritional support in patients with chronic liver disease, Nature Clinical Practice Gastroenterology and Hepatology, (3), Pp 202-209.

4. Bianchi, G., Marzocchi, R., Lorusso, C., Ridolfi, R., \& Marchosini, G., (2008): Nutritional Treatment of Chronic Liver Failure, Hepatology research, Vol. 38, no. 1, S93-S101.

5. Black, J., \& Hawks, J., (2009): Medical Surgical Nursing, Clinical Management for Positive Outcome, 8th ed., Sunders Elsevier, USA, Chapter 47, Pp 1147-1169.

6. Buczko, W., (2010): Cirrhosis and alcoholic hepatitis hospitalization a may medical benefits carries, available at www Google, Com.

7. Cahill, M., Tryniszewski, C., Hubbard, J., Shaw, M., Andrews, M., Cynthia, C., Durkin, M., Christina, L., (1996): Everything you need to know about diseases, Spnnghouse Corporation, available at http://www. spnnghousecorporation/com.htm.

8. Campillo, B., Richardet, J., Scherman, E., \& Bories, P., (2013): Evaluation of nutritional practice in hospitalized cirrhotic patients: results of a prospective study, Nutrition, (19), Pp 515521.

9. Caregaro L., Alberino F., Amodio P., Merkel C., Bolognesi M., and Angeli P., (1996): Malnutrition in alcoholic and virus-related cirrhosis American journal of Clinical Nutrition, (63), Pp. 602-609. Available at: http://www.ajcn.org.

10. Carvalho, L., \& Rober, E., (2006): Evaluation of nutritional status for non- hospitalized patients with liver cirrhosis, Gastroenterology, (43)10, Pp320: 238.

11. Cesario, K., Choure, A., \& Carey, W.,(2011): Complications of Cirrhosis: ascites, Hepatic Encephalopathy, and Variceal Hemorrhage, the Cleveland Clinic Foundation, Center for Continuing Education.

12. David, C., (2011): Definition, epidemiology, and etiology, Division and Gastroenterology and Hepatobiliary diseases, Cirrhosis, New York, Pp 68.

13. Demling, R., \& Desanti, L., (2004): Involuntary weight loss and protein energy malnutrition, diagnosis and treatment, available at http://www MSN. Com.

14. Faiyaz, B., Memon, A., Afsar, S., Qadeer, R., \& Kumar, R., (2007): Correlation of quality of life in patients with liver cirrhosis, etiology and disease severity, journal of Gastroenterology and Hepatology, (19), Pp 2.

15. Faust, T., \& Reedy, K. (2006): The clinician's guide to liver disease, chapter 2, Pp 33.

16. Figueiredo, A., Perz, R., \& Kondo, M., (2005): Effect of liver cirrhosis on body composition: evidence of significant depletion even in mild disease journal of Gastroenterology and Hepatology, Foundation for decision making, 2nded. (20), Pp 209-216.

17. Fusha, J., (2010): Nutritional status in cirrhosis. Journal Hepatology, 21 (3),Pp 317- 25.

18. Guiltinan, A., (2008): Increased all-cause, liver, and cardiac mortality, Pp 20.

19. Gunsar, F., Raimondo, M., Jones, S., Terreni, N., Wong, C., \& Patch, D., (2006): Nutritional status and progress and prognosis in cirrhotic patients, Journal compilation, Pp 24:563-72.

20. Hassan, M., Zaghloul, H., EL- Serag, H., Soliman, Y., Patt, C., ChaPp.ell, R., Beasley, R., \& Hwang, L., (2001): The role of hepatitis c in hepatocellular carcinoma - a case control study among egyptian patients journal clinical Gastroenterology, (33), Pp 123- 126.

21. Hogan, M., \& Madayag, T., (2004): Medical Surgical Nursing: Reviews \& Rationales. News Jersy: Pearson Prentice Hall co, Pp 40.

22. Jennifer, T., Sutri, B., \& Saab, S., (2008): liver transplantation, volume 14, issue $8, \quad \mathrm{Pp}$ 1081:1091.

23. Kawabe, N., Hashimoto, S., \& Yoshioka, K., (2008): Assessment of nutritional status for patient with hepatitis $\mathrm{C}$ virus-related liver cirrhosis, hepatology research, 38 (10), Pp 484490.

24. Kondrup, J., (2007): Nutritional support in liver disease, European Society of Parenteral and Enteral Nutrition (ESPEN), Clinical Nutrition, (27), Pp 305-316.

25. Lacey K., Both S., \& Nelms M., (2008): American Physician Family, Management challenges of liver cirrhosis, 38(11), Pp789-801.

26. Linda, S., \& Paula, D., (2009): Understanding Medical Surgical Nursing, 3rd ed., unit eight, chapter 35, Pp721- 722.

27. Muhlberger, M., Schwarzer, R., Lettmeier, B., Sroczynski, G., Zeuzem, S., \& Siebert, U., (2009): HCV-related burden of disease in Europe: a systematic assessment of incidence, prevalence, morbidity and mortality, BMC Public Health, (1), Pp 9-34. 
28. Nardi, M., Ognana, G., Schiavo, G., \& Caregaro, L. (2009): Nutritional support in liver cirrhosis, Journal of Nutritional Therapy and Metabolism, (27), Pp 155-163. Clinical Nutrition unit, Department of Clinical and Experimental Medicine, university of Padua, Padua - Italy.

29. Nettina, S., (2010): Manual of Nursing Practice, 9th ed., Part Two - Medical-Surgical Nursing, Gastrointestinal and Nutritional Health, chapter 20, Nutritional Problems, Lippincott Williams \& Wilkins.

30. Olde Damink, S., Dejong, C., \& Jalan, R., (2009), Hyperammoneamic and catabolic consequences of upper gastrointestinal bleeding in cirrhosis, Alimantary Pharmacology and Therapeutic, vol. 29, no. 8, Pp801-810.

31. Pablo, A., \& Alday, L., (2010): Assessment of nutritional status on hospital admission, Europe Journal of clinical Nutrition, 57(7), Pp 824- 31.

32. Plauth, M., \& Schutz, E., (2002): Cachexia in liver cirrhosis, International Journal of Cardiology, (85), Pp 83-87.

33. Pugh, R., Murray-Lyon, I., Dawson, J., Pietroni, M., \& Williams, R., (1973): "Transection of the oesophagus for bleeding oesophageal varices". The British journal of

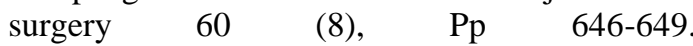
doi:10.1002/bjs.1800600817. PMID 4541913.

34. Rao, M., Naficy, A., Darwish, M., Darwish, N., Schisterman, E., Clemens, J., \& Edelman, R., (2013): Further evidence for association of hepatitis $\mathrm{C}$ infection with parenteral schistosomiasis treatment in Egypt, available at: http://www.PubMed.com.

35. Sallam, I., (2007): The role of parenteral antischistosomal therapy in the spread of HCV in Egypt, available at: http://www.PubMed.com.

36. Sharif, F., Mohebbi, S., Tabtabaee, H., Saberi, M., \& Gholamzadeh, S., (2005): Effect of psycho educational intervention on health related quality of life of patients with chronic liver disease referring to Shiraz university of medical science, available at: http://www.PubMed. com.

37. Stephen, H., (2012), Naperville Gastroenterology, available at: http://napervillegi.com/contrivances/Childpugh.h tm.

38. Tai, K., Siti, H., Mohd, T., Sanjay, R., \& Sanjiv, M., (2010): Anthropometric, biochemical and clinical assessment of malnutrition in Malaysian patients with advanced cirrhosis, Journal of nutrition , (9), 27, Pp 11861475.

39. Vanderplas, S., Iiansen, B., De Boer, J., Stijnen, T., Passo, J., De man, R., \& Schalm, S., (2012): Generic and disease - specific health related quality of life in non-cirrhotic, cirrhotic, and transplanted liver pts, available at: http: //www.Medicine,Come.

40. Walsh, M., \& Crumbie, A., (2007): Clinical Nursing and Related Sciences, 7th ed, Bailliere Tindall Elsevier, Chapter 16,Pp 496 - 510.

41. Weber, J., \& Kelley, J., (2007): Health Assessment in Nursing, 3rded, Lippincott Williams \& Wilkins, chapter 9, Pp 121- 35,

42. WHO, annual report, Rome, (2004).

43. WHO,annual report, Rome, (2014).

44. Yao, Z., Nguyen, D., Hiotellis, A., \& Hahn, Y., (2009), Hepatitis $C$ virus core protein inhibits human $\mathrm{T}$ lymphocyte responses by a complement - Dependent regulatory pathway. Journal of Immunology, (167), 5264 -5272.

45. Zaltron, S., Spinetti, A., Biasi, L., Baiguera, C., \& Castelli, F., (2012): Chronic HCV infection: epidemiological and clinical relevance, BMC Infectious Diseases, , 12(Suppl 2):S2.

46. Zeen El-Abden, H., (2011): Effectiveness of nutritional support on clinical outcomes of patients suffering from liver cirrhosis, thesis of critical care nursing, Tanta University. 